\title{
IDENTIDADE PROFISSIONAL DA ENFERMEIRA: UMA REVISÃO INTEGRATIVA
}

\section{THE PROFESSIONAL IDENTITY OF FEMALE NURSES: AN INTEGRATIVE REVIEW}

\section{LA IDENTIDAD PROFESIONAL DE LA ENFERMERA: REVISIÓN INTEGRATIVA}

\author{
Shirlene Cerqueira Santos ${ }^{1}$ \\ Deybson Borba de Almeida ${ }^{2}$ \\ Gilberto Tadeu Reis da Silva ${ }^{3}$ \\ Glêcia Carvalho Santana ${ }^{1}$ \\ Hudson Soares da Silva ${ }^{4}$ \\ Laiane Silva Santana
}

Como citar este artigo: Santos SC, Almeida DB, Silva GTR, Santana GC, Silva HS, Santana LS. Identidade profissional da enfermeira: uma revisão integrativa. Rev baiana enferm. 2019;33:e29003.

Objetivo: identificar os principais achados em artigos científicos sobre a identidade profissional da enfermeira. Método: estudo do tipo revisão integrativa da literatura, desenvolvido com base na pesquisa bibliográfica sobre artigos científicos a respeito do tema. Utilizada a base de dados da Biblioteca Virtual em Saúde. Compuseram a amostra final 12 publicações científicas. Para análise dos dados, utilizou-se a técnica de análise de conteúdo. Resultados: os dados evidenciaram que a identidade profissional da enfermeira está relacionada com o sentido religioso, com intercessões com os sentidos militar e profissional oriundos da origem da profissão. Conclusão: a identidade profissional da enfermeira está fortemente relacionada com a questão religiosa, sofreu influência da organização militar e apresenta indícios que demonstram seu objetivo de se firmar como profissão e ciência.

Descritores: Enfermeira. Identificação Social. Trabalho Feminino.

Objective: identifying the main findings by scientific articles on the professional identity of female nurses. Method: this is an integrative literature review, developed through a bibliographic research involving scientific articles on the theme. The Virtual Health Library database was used. The final sample was made up of 12 scientific publications. To analyze data, the technique of content analysis was applied. Results: the data made clear that the professional identity of nurses is related to a religious meaning, intersecting with military and professional relations of meaning, which derive from the origins of the profession. Conclusion: the professional identity of female nurses is strongly related to religious issues, has been influenced by military organization, and presents signs that show its objective of being recognized as a profession and a science.

Descriptors: Nurses, Female. Social Identification. Women, Working.

\footnotetext{
Enfermeira. Pesquisadora Independente. Feira de Santana, Bahia, Brasil. shirlene cerqueira@hotmail.com

Enfermeiro. Doutor em Enfermagem. Professor Adjunto. Universidade Estadual de Feira de Santana. Feira de Santana, Bahia, Brasil.

Enfermeiro. Doutor em Ciências. Professor Titular. Universidade Federal da Bahia. Salvador, Bahia, Brasil.

Enfermeiro. Secretaria de Saúde do Estado da Bahia. Prefeitura Municipal de Salvador. Salvador, Bahia, Brasil.

Graduanda em Enfermagem. Universidade Estadual de Feira de Santana. Feira de Santana, Bahia, Brasil.
} 
Objetivo: identificar las mayores descubiertas de artículos científicos sobre la identidad profesional de la enfermera. Método: revisión integrativa de la literatura, desarrollada por medio de una investigación bibliográfica de artículos científicos sobre el tema. Se utilizó la base de datos de la Biblioteca Virtual en Salud. La muestra final se constituyó de 12 publicaciones científicas. Para analizar los datos, se utilizó la técnica de análisis de contenido. Resultados: los dados indicaron que la identidad profesional de la enfermera está relacionada con su sentido religioso y tiene intersecciones con los sentidos militar y profesional, todos derivados de los orígenes de la profesión. Conclusión: la identidad profesional de la enfermera está fuertemente relacionada con la religión, sufrió interferencias de la organización militar, y presenta indicativos del objetivo de establecerse como profesión y ciencia.

Descriptores: Enfermera. Identificación social. Trabajo femenino

\section{Introdução}

A identidade, apresentada como um conceito amplo e complexo, tem sido frequentemente empregada para compreender a inserção do sujeito no mundo e sua relação consigo e com o outro $^{\left({ }_{1}\right)}$. Pode ser concebida como a fonte de significado e experiência de um povo, que não é fixa ou estável, mas histórica e socialmente construída, portanto sujeita a transformações. Contempla a articulação do que é próprio ao indivíduo e o modo como ele imagina ser visto pelos outros $^{(2-3)}$.

Uma das modalidades de identidade é a profissional, definida como "[...] maneiras socialmente reconhecidas para os indivíduos se identificarem uns com os outros, no campo do trabalho e do emprego"(4:17). Uma modalidade de identidade confere ao indivíduo características e especificidades que lhe permitem ser identificado coletiva e socialmente com base no domínio de conhecimentos técnicos e científicos específicos da sua atuação que o capacitam para o exercício profissional $^{(5)}$. A construção da identidade profissional resulta da articulação entre as identidades individual e coletiva. O processo de socialização profissional envolve a aquisição da identidade e o desenvolvimento de sentimentos de pertença, sendo essencial à consolidação de uma identidade profissional ${ }^{(6)}$.

No tocante à identidade profissional da enfermeira, vários estudos problematizam justamente a sua ausência. Este campo profissional apresenta diversos determinantes históricos e sociais que a situam em uma trincheira de exclusão social, subjugação, invisibilidade, falta de identidade dos profissionais que a representam, formação tecnicista, de base proletária, tendo como grande eixo determinista o gênero, que perpassa pela construção social da mulher ${ }^{(7)}$.

A construção da identidade da profissional enfermeira deve ser permeada por laços de identificação com a profissão, tecidos no cotidiano e expressos por meio de sentimentos positivos e negativos acerca da profissão ${ }^{(8)}$. Assim, a enfermeira poderá ser reconhecida por acontecimentos históricos relacionados ao trabalho que exerce, questões de gênero, religião e atuação sociopolítica no campo da saúde.

Quanto à justificativa deste estudo, destaca-se o expressivo contingente de profissionais no Brasil: mais de 400 mil (481.281) enfermeiros, aproximadamente um milhão (1.108.774) de técnicos de enfermagem e cerca de 425 mil (426.022) auxiliares Já na Bahia, estado onde os autores desenvolveram este estudo, atuam, em média, 33 mil (33.026) enfermeiros, 70 mil (71.715) técnicos de enfermagem e 14 mil (14.638) auxiliares ${ }^{(9)}$.

Contudo, apesar do expressivo contingente e da relevância numérica das enfermeiras na equipe de saúde, observa-se fragilidade e conflito na sua identidade profissional. Isto também implica na qualidade do cuidado e/ou da gestão do cuidado exercida por essas profissionais, bem como na falta de clareza das atribuições essenciais para essa trabalhadora e sua centralidade no processo de trabalho em saúde, tanto por parte dos gestores como dos usuários e profissionais de saúde e de enfermagem ${ }^{(7-8)}$. 
Diante do exposto, formulou-se a seguinte questão de pesquisa: Quais os principais achados em artigos científicos sobre a identidade profissional da enfermeira?

Este artigo tem como objetivo, identificar os principais achados em artigos científicos sobre a identidade profissional da enfermeira.

\section{Método}

Trata-se de um estudo do tipo revisão integrativa da literatura, desenvolvido com base na pesquisa bibliográfica de artigos científicos a respeito do tema.

A revisão integrativa configura-se como um tipo de revisão da literatura que reúne dados da literatura teórica e empírica, bem como estudos com distintas abordagens metodológicas (quantitativa e qualitativa) ${ }^{(10-11)}$. Consiste na construção de uma análise mais ampla da literatura, que contribui para discussões sobre métodos e resultados de pesquisas e suscita reflexões acerca da realização de futuras investigações ${ }^{(12)}$. Permite também a síntese de múltiplos estudos e debates acerca de uma área específica de conhecimento $^{(11)}$.

Tal revisão é capaz de gerar uma fonte de conhecimento atual sobre um problema e determinar se tal conhecimento é passível de ser utilizado na prática. No entanto, requer a adoção de padrões de rigor metodológico, a fim de que o leitor possa identificar as principais características dos estudos analisados ${ }^{(13)}$.
Neste estudo, fez-se o levantamento bibliográfico por meio de consulta à base de dados da Biblioteca Virtual em Saúde (BVS). A escolha desta base está assentada na premissa de esta ser direcionada a profissionais de saúde, abranger os países da América Latina e Caribe, possuir uma das melhores coleções de fontes de informação de evidência sobre os efeitos das intervenções em saúde, bem como integrar outros bancos de dados como LILACS, IBECS, MEDLINE, Biblioteca Cochrane e SciELO.

Os critérios de inclusão adotados foram: artigos científicos publicados entre 2012 e 2017, nos idiomas português, espanhol e inglês que fossem encontrados com o cruzamento dos descritores: identidade and enfermagem and enfermeira. A escolha do período adotado para levantamento de dados - 2012 a 2017 - está relacionada com a atualidade das informações na pesquisa científica, bem como com o objetivo de identificar os principais achados sobre identidade profissional da enfermeira coerente com o tempo presente.

Localizou-se um total de 98 artigos, mediante aplicação dos seguintes critérios de exclusão: publicações incompletas, produções em duplicidade e estudos que não abordavam especificamente a identidade profissional da enfermeira. A amostra final foi composta por 12 publicações científicas. O Fluxograma 1 apresenta o processo de seleção dos estudos. 
Fluxograma 1 - Seleção dos estudos para a revisão integrativa

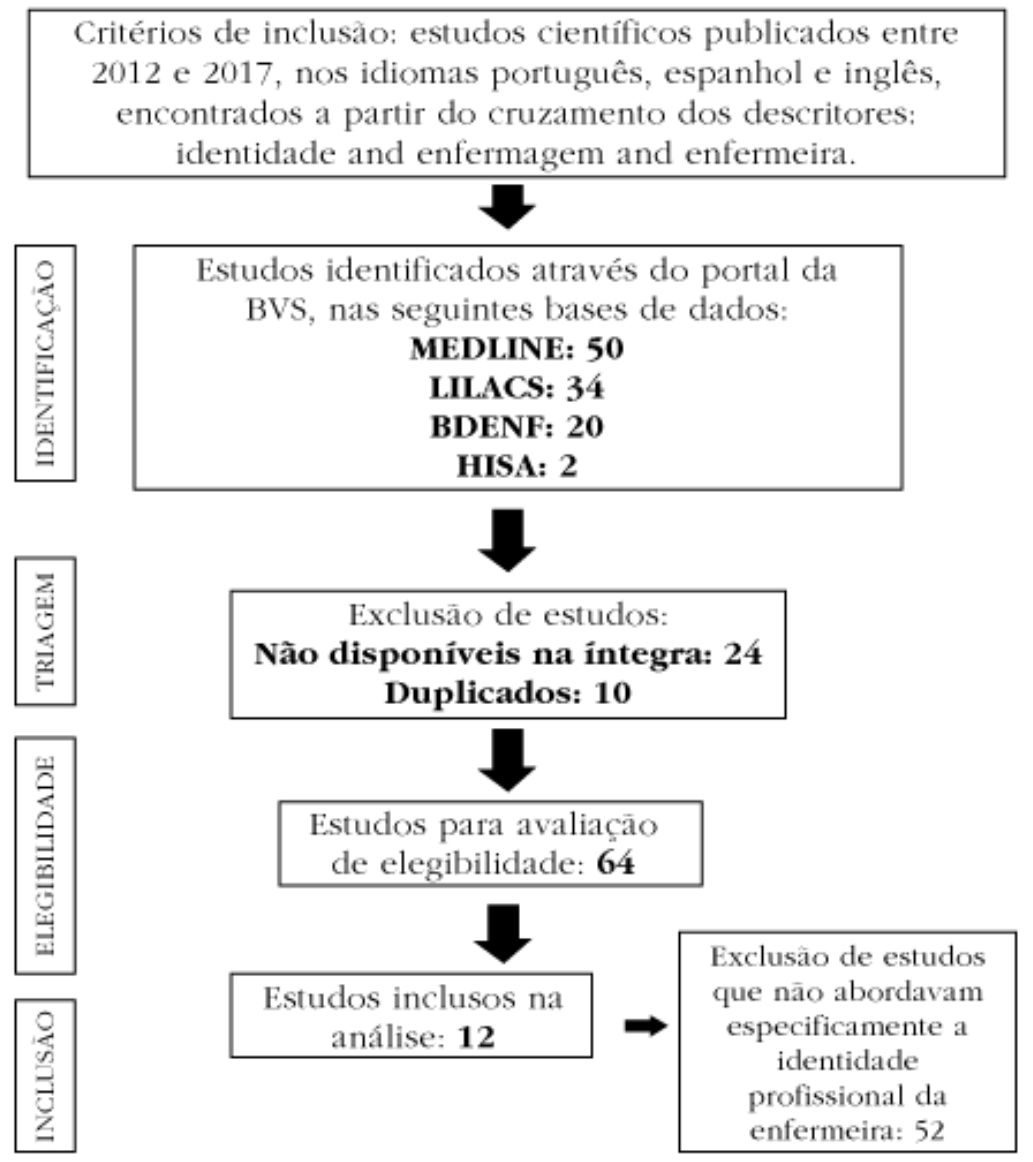

Fonte: Elaboração própria.

Para facilitar a obtenção dos dados de cada estudo, utilizou-se um instrumento de coleta baseado no modelo proposto por Ursi e Pompeu, que permitiu a extração de informações de maneira sistematizada e eficaz ${ }^{(13-14)}$. O instrumento contemplou os seguintes itens: título, revista e ano de publicação, nome dos autores, objetivos do estudo, metodologia utilizada e principais achados (resultados e conclusões). A coleta dos dados que compõem esta revisão ocorreu no período de setembro a outubro de 2017.

A fase de análise das pesquisas incluídas em uma revisão integrativa é complexa, requer tempo e conhecimento do pesquisador. Portanto, deve ser realizada de forma criteriosa, em busca de explicações para os distintos ou conflitantes resultados advindos dos diversos estudos analisados ${ }^{(11-12)}$. Assim, para melhor organização, realizou-se um quadro-síntese contendo informações relativas a cada estudo e utilizou-se a técnica de análise de conteúdo para analisar os resultados.

Em relação aos aspectos éticos desta pesquisa, foram preservadas as autorias de todos os estudos utilizados na elaboração da revisão integrativa, atentando-se para o seu referenciamento. Por ser uma pesquisa de revisão, em que são utilizados apenas dados secundários provenientes de outros estudos, não foi necessário submeter o projeto a um Comitê de Ética em Pesquisa ${ }^{(15)}$.

\section{Resultados}

Nos Quadros 1 a 3 encontra-se uma síntese dos artigos incluídos nesta revisão integrativa, separados de acordo com as categorias construídas na análise de conteúdo. 
Quadro 1 - Identidade profissional da enfermeira e o seu sentido religioso

\begin{tabular}{|c|c|c|c|}
\hline \multicolumn{4}{|c|}{ Categoria 1: Identidade profissional da enfermeira e o seu sentido religioso } \\
\hline Título do artigo & Autores / Ano & Resultados & Identidade \\
\hline $\begin{array}{l}\text { Sobre a } \\
\text { identidade } \\
\text { profissional na } \\
\text { enfermagem: } \\
\text { reconsiderações } \\
\text { pontuais acerca } \\
\text { da visão filosófica }\end{array}$ & $\begin{array}{l}\text { Carvalho V. } \\
2013\end{array}$ & $\begin{array}{l}\text { Identidade profissional definida com base } \\
\text { nos pressupostos nightingaleanos (caráter } \\
\text { doutrinário, caritativo, submisso e amoroso). } \\
\text { Atuação profissional precária, com fragilidade } \\
\text { técnica e cientifica. }\end{array}$ & Religiosa \\
\hline $\begin{array}{l}\text { Portuguese } \\
\text { nursing: history } \\
\text { of the life and } \\
\text { activism of Maria } \\
\text { Augusta Sousa }\end{array}$ & $\begin{array}{l}\text { Almeida DB, Silva } \\
\text { GTR, Queirós PJP, } \\
\text { Freitas GF, Laitano } \\
\text { ADC, Almeida SS, } \\
\text { et al. }{ }^{(17)} \\
2016\end{array}$ & $\begin{array}{l}\text { A fragilidade política da enfermagem } \\
\text { permeada por uma formação tecnicista, com } \\
\text { forte influência religiosa, que guarda relação } \\
\text { com a discussão de gênero, isto é, com o } \\
\text { papel social da mulher e sua consequente } \\
\text { construção social. }\end{array}$ & Religiosa \\
\hline $\begin{array}{l}\text { Cuidado: essência } \\
\text { da identidade } \\
\text { profissional da } \\
\text { Enfermagem }\end{array}$ & $\begin{array}{l}\text { Oguisso T, Freitas } \\
\mathrm{GF}^{(18)} \\
2016\end{array}$ & $\begin{array}{l}\text { Enfermagem exercida quase exclusivamente } \\
\text { por mulheres. } \\
\text { As enfermeiras eram facilmente identificadas } \\
\text { pela touca, considerada um dos itens da } \\
\text { vestimenta de religiosas. } \\
\text { O cuidado como atividade doméstica } \\
\text { praticado por mulheres, tornando-se invisível } \\
\text { e desvalorizado socialmente. } \\
\text { Divisão técnica e social do trabalho na } \\
\text { enfermagem. }\end{array}$ & Religiosa \\
\hline $\begin{array}{l}\text { Vestuário de } \\
\text { alunas de } \\
\text { uma escola de } \\
\text { enfermagem } \\
\text { brasileira: } \\
\text { relações com } \\
\text { a identidade } \\
\text { profissional } \\
\text { (1947-1965) }\end{array}$ & $\begin{array}{l}\text { Almeida RLM, } \\
\text { Aperibense PGGS, } \\
\text { Rodrigues AAP, } \\
\text { Figueiredo MAG, } \\
\text { Santos TCF, } \\
\text { Almeida Filho AJ, } \\
\text { et al. } \\
2016\end{array}$ & $\begin{array}{l}\text { As divisas na manga do vestido e a touca da } \\
\text { aluna simbolizavam identidade e hierarquia, } \\
\text { além de assemelharem-se às vestimentas de } \\
\text { religiosas. } \\
\text { Reprodução de comportamentos como zelo } \\
\text { e orgulho do uniforme, que deveria ser } \\
\text { usado não somente como uma vestimenta } \\
\text { que cobria o corpo, mas enquanto } \\
\text { simbologia gradativamente incorporada } \\
\text { pelas alunas de enfermagem e enfermeiras } \\
\text { diplomadas. }\end{array}$ & Religiosa \\
\hline
\end{tabular}

Fonte: Elaboração própria.

Quadro 2 - Intercessão da identidade religiosa e profissional da enfermeira

Categoria 2: Intercessão da identidade religiosa e profissional da enfermeira

\begin{tabular}{|c|c|c|c|}
\hline Título do artigo & Autores/Ano & Resultados & Identidade \\
\hline $\begin{array}{l}\text { Teorias de } \\
\text { enfermagem e } \\
\text { modelos que } \\
\text { fortalecem a prática } \\
\text { profissional }\end{array}$ & $\begin{array}{l}\text { Porto AR, Thofehrn } \\
\text { MB, Pai DD, } \\
\text { Amoestoy SC, Joner } \\
\text { LR, Palma JS } \\
2013\end{array}$ & $\begin{array}{l}\text { A profissão ainda apresenta a } \\
\text { necessidade de ocupar espaços de } \\
\text { poder e capacitar este profissional sob } \\
\text { a perspectiva de um ser sociopolítico, } \\
\text { uma vez que lida constantemente com } \\
\text { uma crise de identidade em virtude da } \\
\text { dependência teórico-prática de outras } \\
\text { profissões da área da saúde. }\end{array}$ & $\begin{array}{c}\text { Religiosa } \\
\mathrm{x} \\
\text { Profissional }\end{array}$ \\
\hline
\end{tabular}


Quadro 2 - Intercessão da identidade religiosa e profissional da enfermeira (conclusão)

Categoria 2: Intercessão da identidade religiosa e profissional da enfermeira

\begin{tabular}{|c|c|c|c|}
\hline Título do artigo & Autores/Ano & Resultados & Identidade \\
\hline $\begin{array}{l}\text { Contribuição do } \\
\text { Projeto HOPE para } \\
\text { a configuração } \\
\text { da identidade } \\
\text { profissional } \\
\text { das primeiras } \\
\text { enfermeiras } \\
\text { alagoanas, de } 1973 \\
\text { a } 1977\end{array}$ & $\begin{array}{l}\text { Costa LMC, Santos } \\
\text { RM, Santos TCF, } \\
\text { Trezza MCSF, Leite } \\
\text { JL }^{(21)} \\
2014\end{array}$ & $\begin{array}{l}\text { Profissão meramente auxiliar dos } \\
\text { médicos, de caráter altamente técnico- } \\
\text {-científico e combativa no trato das } \\
\text { questões políticas da saúde e da } \\
\text { autonomia da profissão. }\end{array}$ & $\begin{array}{c}\text { Religiosa } \\
\mathrm{x} \\
\text { Profissional }\end{array}$ \\
\hline $\begin{array}{l}\text { A visão discente } \\
\text { sobre a identidade } \\
\text { profissional do } \\
\text { enfermeiro }\end{array}$ & $\begin{array}{l}\text { Pinto DPSR, } \\
\text { Câmara AG, } \\
\text { Malveira FAS, } \\
\text { Valença CN, } \\
\text { Germano RM, } \\
\text { Ferreira Júnior } \\
\text { MA }^{(22)} \\
2014\end{array}$ & $\begin{array}{l}\text { Estudantes de graduação expressaram } \\
\text { que os principais aspectos envolvidos } \\
\text { na identidade profissional do enfermeiro } \\
\text { são a capacidade de liderança, de atuar } \\
\text { como educador, dispor de conhecimento } \\
\text { técnico-científico, ser humilde e capaz de } \\
\text { apreender as necessidades e dificuldades } \\
\text { do outro. }\end{array}$ & $\begin{array}{c}\text { Religiosa } \\
\mathrm{x} \\
\text { Profissional }\end{array}$ \\
\hline $\begin{array}{l}\text { Identidade } \\
\text { profissional } \\
\text { percebida por } \\
\text { acadêmicos de } \\
\text { enfermagem: } \\
\text { atuação, } \\
\text { reconhecimento e } \\
\text { valorização }\end{array}$ & $\begin{array}{l}\text { Beck CLC, } \\
\text { Prestes FC, Silva } \\
\text { RM, Tavares JP, } \\
\text { Prochnow A } \\
2014\end{array}$ & $\begin{array}{l}\text { Dificuldade de definir as atribuições } \\
\text { da enfermagem, segmentação da } \\
\text { profissão em categorias e cultura de } \\
\text { supervalorização da classe médica. }\end{array}$ & $\begin{array}{c}\text { Religiosa } \\
\mathrm{x} \\
\text { Profissional }\end{array}$ \\
\hline $\begin{array}{l}\text { Uniform as a sign } \\
\text { of a new nursing } \\
\text { identity in Brasil } \\
(1923-1931)\end{array}$ & $\begin{array}{l}\text { Peres MAA, Padilha } \\
\text { MICS }^{(24)} \\
2014\end{array}$ & $\begin{array}{l}\text { O uso oficial do uniforme na Escola } \\
\text { Anna Nery (EAN) foi parte importante } \\
\text { da estratégia de construir uma nova } \\
\text { identidade profissional, sendo utilizado } \\
\text { como um símbolo. } \\
\text { A ausência de avental (que caracteriza o } \\
\text { trabalho como doméstico) no uniforme } \\
\text { das diplomadas, cujos principais } \\
\text { elementos simbólicos são a cor branca } \\
\text { (por questões higiênicas, permitiu-se que } \\
\text { fosse substituído o tecido escuro, usado } \\
\text { pelas religiosas) e a touca (como símbolo } \\
\text { da enfermagem profissional). }\end{array}$ & $\begin{array}{c}\text { Religiosa } \\
\mathrm{x} \\
\text { Profissional }\end{array}$ \\
\hline $\begin{array}{l}\text { Sistematização } \\
\text { da Assistência } \\
\text { de Enfermagem } \\
\text { e formação } \\
\text { da identidade } \\
\text { profissional }\end{array}$ & $\begin{array}{l}\text { Gutiérrez MGR, } \\
\text { Morais SCRV } \\
2017\end{array}$ & $\begin{array}{l}\text { Escassez de discussões sobre as } \\
\text { repercussões para a construção do } \\
\text { conhecimento genuíno de enfermagem } \\
\text { e consequentemente da identidade } \\
\text { profissional, além de limitada utilização } \\
\text { de referenciais teóricos de enfermagem } \\
\text { que norteiem o uso dessa ferramenta na } \\
\text { prestação de cuidados. } \\
\text { Descrédito que parte das categorias de } \\
\text { enfermagem tem manifestado em relação } \\
\text { ao uso da Sistematização da Assistência } \\
\text { de Enfermagem (SAE) enquanto diretriz } \\
\text { promotora da qualidade do cuidado e da } \\
\text { autonomia profissional. }\end{array}$ & $\begin{array}{c}\text { Religiosa } \\
\mathrm{x} \\
\text { Profissional }\end{array}$ \\
\hline
\end{tabular}

Fonte: Elaboração própria. 
Quadro 3 - Intercessão da identidade militar e religiosa da enfermeira

\begin{tabular}{|c|c|c|c|}
\hline \multicolumn{4}{|c|}{ Categoria 3: A intercessão da identidade militar e religiosa da enfermeira } \\
\hline Título do artigo & Autores/Ano & Resultados & Identidade \\
\hline $\begin{array}{l}\text { Rituales patrióticos } \\
\text { y religiosos: } \\
\text { contribución a } \\
\text { la identidad de } \\
\text { las enfermeras } \\
\text { brasileña y } \\
\text { española (1937- } \\
\text { 1945) }\end{array}$ & $\begin{array}{l}\text { Santos TCF, Oliveira } \\
\text { AB, Gomes MLB, } \\
\text { Peres MAA, Almeida } \\
\text { Filho AJ, Abrão } \\
\text { FMS }^{(26)} \\
2013\end{array}$ & $\begin{array}{l}\text { A participação de mulheres na guerra } \\
\text { originou enfermeiras militares, que } \\
\text { atuaram como voluntárias motivadas } \\
\text { pelo compromisso com o exercício da } \\
\text { profissão. } \\
\text { A enfermeira apresentava qualidades de } \\
\text { dona de casa ideal e valores tradicionais } \\
\text { de submissão, dedicação e devoção para } \\
\text { com as necessidades do paciente e do } \\
\text { médico. } \\
\text { A religião também emergiu como } \\
\text { justificativa para o trabalho da enfermeira. } \\
\text { Nesse sentido, o caráter de sacrifício era } \\
\text { uma qualidade considerada essencial às } \\
\text { enfermeiras. } \\
\text { A divisão do trabalho da enfermagem } \\
\text { também sofreu grande influência militar, } \\
\text { visto que, nessa época, iniciou-se uma } \\
\text { divisão de trabalho entre as enfermeiras } \\
\text { que supervisionavam e aqueles } \\
\text { diretamente ligados à assistência. }\end{array}$ & $\begin{array}{c}\text { Militar } \\
\text { x } \\
\text { Religiosa }\end{array}$ \\
\hline $\begin{array}{l}\text { Sexist stereotypes } \\
\text { in portuguese } \\
\text { nursing: A } \\
\text { historical study in } \\
\text { the period } 1935 \text { a } \\
1974\end{array}$ & $\begin{array}{l}\text { Almeida DB, } \\
\text { Queirós PJP, Silva } \\
\text { GTR, Laitano ADC, } \\
\text { Almeida SS } \\
2016\end{array}$ & $\begin{array}{l}\text { Influência das forças armadas na profissão } \\
\text { e a enfermagem militar (divisão social do } \\
\text { trabalho, com características de trabalho } \\
\text { voluntário e caritativo). } \\
\text { Enfermagem como campo de trabalho } \\
\text { feminino e de gênero como uma } \\
\text { formação social (indução da mulher para } \\
\text { ações consideradas “domésticas", por } \\
\text { exemplo, o cuidado para com outras } \\
\text { pessoas). } \\
\text { Enfermagem como sacerdócio (prática } \\
\text { realizada com desvelo, caritativa, } \\
\text { moralizada e abnegada). } \\
\text { Enfermagem como saber auxiliar (fazer, } \\
\text { desarticulado de formação sistemática e } \\
\text { científica). }\end{array}$ & $\begin{array}{c}\text { Militar } \\
\text { x } \\
\text { Religiosa }\end{array}$ \\
\hline
\end{tabular}

Fonte: Elaboração própria.

\section{Discussão}

Para melhor compreensão das categorias que emergiram da análise dos estudos incluídos nesta revisão integrativa, optou-se por iniciar a discussão pela identidade profissional da enfermeira e o seu sentido religioso, por ter sido a dimensão de maior ocorrência.

O sentido religioso presente na identidade profissional da enfermeira tem sua origem no período medieval. Nesse momento, as práticas de saúde eram influenciadas pelos determinantes políticos e socioeconômicos presentes na sociedade feudal e nas suas relações com o cristianismo e caracterizaram o primeiro movimento de institucionalização do cuidado e sua vinculação à imagem sacerdotal. Data dessa época a origem da Enfermagem como prática leiga, desenvolvida maioritariamente por religiosas, deixando um legado de valores que, 
com o decorrer do tempo, foram legitimados e aceitos pela sociedade como atributos inerentes às enfermeiras ${ }^{(7,28)}$.

Nesse sentido, a submissão e a obediência foram amplamente abordadas na maioria dos estudos analisados, sendo ambas características marcantes das religiosas que, à época, foram transferidas para a Enfermagem. Isto fez com que essa fosse compreendida como uma profissão hierarquicamente inferior e, portanto, subordinada à medicina ${ }^{(29)}$.

A abnegação, devoção, dedicação, espírito de serviço e obediência foram socialmente atribuídos ao trabalho da enfermeira com o objetivo de conferir-lhe um caráter mais de sacerdócio do que de prática profissional, uma vez que as atividades estavam centradas no fazer manual e baseavam-se em conhecimentos empíricos ${ }^{(28)}$. Assim, predominavam ações de saúde caseiras e populares e intensa conotação mística e sentimental de caridade cristã.

Destaca-se que, mesmo após a profissionalização na área de Enfermagem, as características do fazer religioso permaneceram presentes. Isto porque sua principal precursora, Florence Nightingale, enfatizava que as atividades do campo da enfermagem deveriam ser compreendidas tanto como vocação quanto como profissão. Portanto, ambos os aspectos eram indissociáveis ${ }^{(30)}$.

Dessa forma, autores assinalam que a propagação do ideário original de que a Enfermagem era uma área de atuação feminina e caritativa contribuiu para a marginalização e desvalorização da enfermeira. Assim, ela foi destituída de valor social enquanto profissional, por ser obediente e submissa às determinações de outros profissionais da saúde. Tal situação, por sua vez, acentuou a falta de clareza sobre a importância de sua atuação para a equipe de saúde, pacientes e sociedade de modo geral ${ }^{(29,31)}$.

A convergência entre a identidade religiosa e a profissional da enfermeira tem sua origem no nascimento da Enfermagem moderna, influenciada pelos saberes e práticas de Florence Nightingale. Nesse momento, teve início a prática profissional institucionalizada e específica, que conquistou respeito na área da saúde. Assim, deixou de ser concebida como mera atividade empírica e passou a ser reconhecida como categoria profissional assalariada, a fim de atender à necessidade de mão de obra nos hospitais. Desde então, essa profissão passou a requerer uma atuação fundamentada em saber científico $^{(32)}$.

No entanto, nos estudos analisados, a profissionalização na área da Enfermagem foi discutida como prática que, por mais que adquirisse cientificidade, permaneceu por longo período permeada por traços marcantes da influência religiosa na profissão. Isto se observava tanto por algumas características atribuídas socialmente às enfermeiras quanto pela própria personalização do seu uniforme, que se assemelhava ao das religiosas $^{(24)}$.

Cabe mencionar que, nessa época, a atuação das enfermeiras pautava-se na dimensão prática das técnicas e do saber administrativo, o que representava o processo de trabalho da Enfermagem, pela divisão técnica verticalizada, dicotomia que distingue seu saber/fazer pela formação ${ }^{(33)}$.

Segundo alguns autores, o modelo de Enfermagem preconizado por Florence (Sistema Nightingaleano) foi um dos principais responsáveis pela propagação da desvalorização e vulnerabilização do trabalho desempenhado pelas enfermeiras, pois impunha inúmeras exigências àquelas contratadas, a saber: serem solteiras, sem filhos e completamente submissas às exigências das instituições de saúde e às determinações da classe médica. Isso facilitava a sua exploração pelo Estado e pelos serviços de saúde. De acordo com um dos estudos analisados, tratava-se de algo similar ao trabalho escravo e àquele realizado pelas irmãs de caridade ${ }^{(17)}$.

A divisão social e técnica do trabalho na área de Enfermagem originou condições essenciais para compreender a construção da identidade de enfermeiras, pois fez com que as atividades por elas realizadas não fossem bem delimitadas, o que, com frequência, gerava equivocadas compreensões de sua atuação ${ }^{(17)}$. Esse aspecto foi evidenciado também em outro estudo, que 
assinalou a dificuldade dos discentes de Enfermagem em distinguir quais eram as atividades específicas da enfermeira, associando, na maioria das vezes, características presentes em ações de cunho religioso $^{(22)}$.

Os estudos que abordaram a identidade da enfermeira associada a aspectos religiosos e militares mostraram que elas foram recrutadas para trabalhar na guerra como voluntárias, motivadas por valores tradicionais de submissão, dedicação e devoção para com as necessidades do paciente e do médico, tendo a religião como justificativa para esse trabalho ${ }^{(17,26)}$. A principal atividade que desenvolviam nos campos de batalha era o cuidado direto aos soldados feridos, por ser concebido como prática exclusivamente feminina, em virtude da relação com o trabalho doméstico.

No Brasil, foi durante a I Guerra Mundial, em 1914, que a Cruz Vermelha assumiu o preparo de enfermeiras voluntárias, para que auxiliassem os feridos na guerra ${ }^{(28)}$. Válido mencionar que, uma vez adaptadas ao cotidiano da guerra e às adversidades dos acampamentos, poderiam apreender novas culturas e tecnologias ${ }^{(34)}$.

A divisão social do trabalho da Enfermagem também foi aspecto discutido nos estudos. A profissão sofreu grande influência da organização militar, em especial do conceito da unidade de comando presente na organização linear, tendo suas origens no exército e na época medieval $^{(35)}$. Isto explica, em parte, a dicotomia entre o pensar e o fazer na Enfermagem, intrinsecamente relacionada à divisão técnica e social do trabalho, pois as ações intelectuais eram delegadas às denominadas ladies nurses, enquanto as ações manuais ficavam sob a responsabilidade das nurses $^{(28)}$, levando a uma desvalorização do cuidado prestado pela enfermeira. Além disso, tais estereótipos contribuíram para a propagação da imagem da Enfermagem como prática auxiliar à medicina, pautada em ações manuais e desarticuladas, decorrentes de uma formação sistematizada e científica ${ }^{(28)}$.

Com base na análise dos diversos fatores relacionados à construção da identidade profissional da enfermeira, infere-se que a atual percepção da identidade, associada ao seu reconhecimento ou não como tal, contribui para uma frágil identificação, uma vez que as ações atribuídas a esta profissão denotam uma incompletude (o quase ser), aspecto que repercute diretamente em atribuições próprias dessas profissionais, bem como na sua autonomia, realização pessoal e no reconhecimento da Enfermagem enquanto profissão ${ }^{(8)}$.

Não se pode negar que o trabalho das profissionais da área de Enfermagem é permeado por processos e intercâmbios políticos e sociais, os quais, muitas vezes, dificultam compreender a real importância dessas trabalhadoras, que se encontram envoltas pelo tecnicismo e pela multiplicidade de vínculos empregatícios, em um universo de precarização do trabalho. Nesse contexto, são frequentemente violentadas simbolicamente, ao mesmo tempo em que também praticam violência contra as categorias a elas subalternas no cotidiano das relações profissionais $^{(7)}$.

Entretanto, as amplas transformações sociais e econômicas atuais impuseram inúmeras mudanças no mundo do trabalho e, por conseguinte, nas identidades. Isso possibilita às enfermeiras, enquanto grupo profissional, reivindicarem novas identidades que transcendam dialeticamente as marcas do passado ${ }^{(36)}$.

Nesse sentido, evidencia-se a necessidade de uma atuação mais crítica e reflexiva por parte das enfermeiras no que se refere ao exercício de sua profissão, para que assumam uma postura efetivamente engajada na luta por melhores condições de trabalho. Destaca-se que, se isso não ocorrer, o futuro da Enfermeira será a intensificação tanto do barateamento da força de trabalho como sua proletarização, repercutindo ainda mais na fragilidade política e crítica de seus profissionais ${ }^{(37)}$.

\section{Conclusão}

Este estudo pôde concluir que a identidade profissional da enfermeira está fortemente relacionada com a questão religiosa, sofreu influência da organização militar e apresenta indícios que demonstram seu objetivo de se firmar 
como profissão e ciência. Paralelamente, permanece permeada por aspectos relacionados à construção sócio-histórica da profissão (gênero, submissão e desvalorização profissional).

Assim, é de suma importância promover discussões sobre a identidade profissional da enfermeira nos espaços de formação e atuação profissional, pois isso contribuirá para construir e consolidar uma identidade de fato impulsionadora de reconhecimento social e valorização profissional.

Tais discussões podem ainda favorecer a compreensão do seu processo e objeto de trabalho, assim como reafirmar e consolidar o papel central que ocupa em relação às outras categorias profissionais na área da saúde. Como consequência, haverá engajamento profissional e será contemplada a dimensão política da profissão em prol de um cuidado mais humano, político e ético.

\section{Colaborações:}

1. concepção, projeto, análise e interpretação dos dados: Shirlene Cerqueira dos Santos e Deybson Borba de Almeida;

2. redação do artigo e revisão crítica relevante do conteúdo intelectual: Gilberto Tadeu Reis da Silva, Glêcia Carvalho Santana, Hudson Soares da Silva e Laiane Silva Santana;

3. aprovação final da versão a ser publicada: Shirlene Cerqueira dos Santos e Deybson Borba de Almeida.

\section{Referências}

1. Avelar VLLM, Paiva KCM. Configuração identitária de enfermeiros de um serviço de atendimento móvel de urgência. Rev bras enferm [Internet]. 2010 [cited 2017 Sep 2];63(6):1010-8. DOI: http:// dx.doi.org/10.1590/S0034-71672010000600022

2. Castells M. O poder da identidade. 2a ed. São Paulo: Paz e Terra; 1999.

3. Hall S. A identidade na pós-modernidade. 11a ed. Rio de Janeiro: DP\&A; 2006.

4. Dubar C. A crise das identidades: a interpretação de uma mutação. São Paulo: EDUSP; 2009.
5. Bellaguarda MLR, Silveira LR, Mesquita MPL, Ramos FRS. Identidade da profissional enfermeira caracterizada numa revisão integrativa. Enferm foco [Internet]. 2011 [cited 2017 Sep 3];2(3):180-3. Available from: http://biblioteca.cofen.gov.br/ wpcontent/uploads/2016/01/Identidade-daprofissional-enfermeira-caracterizada-numarevisao-integrativa.pdf

6. Moreno LA, Pupuche RB, Ayala RL. Formación de la identidad profesional en las estudiantes de la facultad de enfermería de una Universidad en Lambayeque. Rev iberoam educ invest en enferm [Internet]. 2012 [cited 2017 Sep 25];2(3):33-9. Available from: http://www.enfermeria21.com/ revistas/aladefe/articulo/45/

7. Almeida DB. Constituição de enfermeiras militantes: um estudo histórico e foucaultiano [Internet] [tese]. Salvador (BA): Universidade Federal da Bahia; 2017 [cited 2017 Sep 14]. Available from: https://pgenf. ufba.br/pt-br/teses-e-dissertacoes?field_categoria_ teses_tid=All\&field_autor_tesess_value $=\&$ field_ orientador_tesess_value $=\&$ title $=\&$ field_anos_ teses_value[value]\&field_linhas_pesquisa_teses_ value $=$ All\&page $=1$

8. Vilela GS. Configuração identitária do enfermeiro da estratégia de saúde da família de um município do interior do estado de Minas Gerais [Internet] [tese]. Belo Horizonte (MG): Universidade Federal de Minas Gerais; 2014 [cited 2017 Sep 28]. Available from: http://www.bibliotecadigital.ufmg. br/dspace/handle/1843/ANDO-9KYPQS

9. Conselho Federal de Enfermagem. Enfermagem em números. Quantitativo de profissionais por regional [Internet]. Brasília; 2017 [cited 2017 Oct 21]. Available from: http://www.cofen.gov.br/ enfermagem-em-numeros

10. Soares CB, Hoga LAK, Peduzzi M, Sangaleti C, Yonekura $\mathrm{T}$, Silva DRAD. Integrative review: concepts and methods used in nursing. Rev esc enferm USP [Internet]. 2014 [cited 2017 Oct 12];48(2):335-45. DOI: http://dx.doi.org/10.1590/ S0080-623420140000200020

11. Pompeo DA, Rossi LA, Galvão CM. Integrative literature review: the initial step in the validation process of nursing diagnoses. Acta paul enferm [Internet]. 2009 [cited 2017 Sep 1];22(4):434-8. DOI: http://dx.doi.org/10.1590/ S0103-21002009000400014

12. Mendes KDS, Silveira RCCP, Galvão CM. Revisão integrativa: método de pesquisa para a incorporação de evidências na saúde e na enfermagem. Texto 
contexto-enferm [Internet]. 2008 [cited 2017 Sep 3];17(4):758-64. DOI: http://dx.doi.org/10.1590/ S0104-07072008000400018

13. Pompeo DA. Diagnóstico de enfermagem náusea em pacientes no período pós-operatório imediato: revisão integrativa da literatura [Internet] [tese]. Ribeirão Preto (SP): Universidade de São Paulo; 2007 [cited 2017 Oct 5]. Available from: http:// www.teses.usp.br/teses/disponiveis/22/22132/ tde-15102007-140328/pt-br.php

14. Ursi ES. Prevenção de lesões de pele no perioperatório: revisão integrativa da literatura [Internet] [tese]. Ribeirão Preto (SP): Universidade de São Paulo; 2005 [cited 2017 Oct 5]. Available from: http://www.teses.usp.br/teses/ disponiveis/22/22132/tde-18072005-095456/pt-br. php

15. Brasil. Ministério da Saúde. Resolução n. 466/12, de 12 de dezembro de 2012. Aprova as diretrizes e normas regulamentadoras de pesquisas envolvendo seres humanos. Brasília (DF); 2012 [cited 2017 Oct 5]. Available from: http://bvsms.saude.gov.br/bvs/ saudelegis/cns/2013/res0466_12_12_2012.html

16. Carvalho V. Sobre a identidade profissional na enfermagem: reconsiderações pontuais em visão filosófica. Rev bras enferm [Internet]. 2013 [cited 2017 Oct 12];66(esp):24-32. DOI: http://dx.doi. org/10.1590/S0034-71672013000700003

17. Almeida DB, Silva GTR, Queirós PJP, Freitas GF, Laitano ADC, Almeida SS, et al. Portuguese nursing: history of the life and activism of Maria Augusta Sousa. Rev esc enferm USP [Internet]. 2016 [cited 2017 Sep 29];50(3):498-504. DOI: http://dx.doi. org/10.1590/S0080-623420160000400017

18. Oguisso T, Freitas GF. Cuidado: essência da identidade profissional da Enfermagem. Rev esc enferm USP [Internet]. 2016 [cited 2017 Oct 1];50(2):188-9. DOI: http://dx.doi.org/10.1590/ S0080-623420160000200001

19. Almeida RLM, Aperibense PGGS, Rodrigues AAP, Figueiredo MAG, Santos, TCF, Almeida Filho AJ, et al. Vestuário de alunas de uma escola de enfermagem brasileira: relações com a identidade profissional (1947-1965). Cienc enferm [Internet]. 2016 [cited 2017 Oct 10];22(3):125-36. DOI: http:// dx.doi.org/10.4067/S0717-95532016000300125

20. Porto AR, Thofehrn MB, Pai DD, Amoestoy SC, Joner LR, Palma JS. Teorias de enfermagem e modelos que fortalecem a prática profissional. Rev pesqui cuid fundam (Online). 2013 [cited 2017 Oct
22];5(5 n esp):155-61. Available from: http://www. seer.unirio.br/index.php/cuidadofundamental/ article/view/1720/pdf_1017

21. Costa LMC, Santos RM, Santos TCF, Trezza MCSF, Leite JL. Contribuição do Projeto HOPE para a configuração da identidade profissional das primeiras enfermeiras alagoanas, 1973 a 1977. Rev bras enferm [Internet]. 2014 [cited 2017 Oct 15];67(4):536-42. DOI: http://dx.doi. org/10.1590/0034-7167.2014670406

22. Pinto DPSR, Câmara AG, Malveira FAS, Valença CN, Germano R, Ferreira Júnior MA. A Visão discente sobre a identidade profissional do enfermeiro. Rev iberoam educ invest enferm [Internet]. 2014 [cited 2017 Sep 17];4(3):36-42. Available from: http://www.enfermeria21.com/revistas/aladefe/ articulo/132/

23. Beck CLC, Prestes FC, Silva RM, Tavares JP, Prochnow A. Identidade profissional percebida por acadêmicos de enfermagem: atuação, reconhecimento e valorização. Rev enferm UERJ [Internet]. 2014 [cited 2017 Sep 22];22(2):200-5. Available from: http://www.e-publicacoes. uerj.br/index.php/enfermagemuerj/article/ view/13587/10397

24. Peres MAA, Padilha MICS. Uniform as a sign of a new nursing identity in Brazil (19231931). Esc Anna Nery [Internet]. 2014 [cited 2017 Oct 4];18(1):112-21. DOI: http://dx.doi. org/10.5935/1414-8145.20140017

25. Gutiérrez MGR, Morais SCRV. Sistematização da Assistência de Enfermagem e formação da identidade profissional. Rev bras enferm [Internet]. 2017 [cited 2017 Oct 27];70(2):455-60. DOI: http:// dx.doi.org/10.1590/0034-7167-2016-0515

26. Santos TCF, Oliveira AB, Gomes MLB, Peres MAA, Almeida Filho AJ, Abrão FMS. Rituales patrióticos y religiosos: contribución a la identidad de las enfermeras brasileña y española (1937-1945). Esc Anna Nery [Internet]. 2013 [cited 2017 Oct 6];17(1):104-10. DOI: http://dx.doi.org/10.1590/ S1414-81452013000100015

27. Almeida DB, Queirós PJP, Silva GTR, Laitano ADC, Almeida SS. Sexist stereotypes in portuguese nursing: A historical study in the period 1935 to 1974. Esc Anna Nery [Internet]. 2016 [cited 2017 Oct 25];20(2):228-35. DOI: http://dx.doi. org/10.5935/1414-8145.20160030

28. Geovanini T, Moreira A, Schoeller SD, Machado WCA. História da Enfermagem: versões e 
interpretações. 3a ed. Rio de Janeiro: Revinter; 2010.

29. Passos ES. De anjos a mulheres: ideologias e valores na formação de enfermeiras. 2a ed. Salvador: EDUFBA; 2012.

30. Costa R, Padilha MI, Amante LN, Costa E, Bock LF. O legado de Florence Nightingale: uma viagem no tempo. Texto contexto-enferm [Internet]. 2009 [cited 2017 Sep 8];18(4):661-9. DOI: http://dx.doi. org/10.1590/S0104-07072009000400007

31. Avila LI, Silveira RS, Lunardi VL, Fernandes GFM, Mancia JR, Silveira JT. Implications of the visibility of professional nursing practices. Rev gaúcha enferm [Internet]. 2013 [cited 2017 Sep 10];34(3):102-9. DOI: http://dx.doi.org/10.1590/ S1983-14472013000300013

32. Oguisso T, Campos PFS, Moreira A. Enfermagem pré-profissional no Brasil: questões e personagens. Enferm foco [Internet]. 2011 [cited 2017 Sep 16];2:68-72. Available from: http://revista.cofen. gov.br/index.php/enfermagem/article/view/85/71

33. Teodosio SS-CS, Enders BC, Lira ALBC, Padilha MI, Breda KL. Análise do conceito de Identidade Profissional do Enfermeiro. Atas-Investigação qualitativa saúde [Internet]. 2017 [cited 2017 Oct
13];2:1588-96. Available from: http://proceedings. ciaiq.org/index.php/ciaiq2017/article/view/1511

34. Bernardes MMR, Lopes GT, Santos TCF. O cotidiano das enfermeiras do Exército na Força Expedicionária Brasileira (FEB) no Teatro de Operações da $2^{\underline{a}}$ Guerra Mundial, na Itália (19421945). Rev latino-am enferm [Internet]. 2005 [cited 2017 Oct 9];13(3):314-21. DOI: http://dx.doi. org/10.1590/S0104-11692005000300005

35. Kurcgant P. Gerenciamento em enfermagem. Rio de Janeiro: Guanabara Koogan; 2005.

36. Pereira JG, Oliveira MAC, Yamashita $\mathrm{CH}$. Identidade profissional da enfermeira no Brasil: passado, presente e futuro. Trabalho apresentado no Congresso Internacional de Humanidades \& Humanização em Saúde. São Paulo; 2014. Anais (on-line). Blucher Med Proceed [Internet]. 2014 [cited 2017 Oct 2];1(2):89. DOI: http://dx.doi. org/10.5151/medpro-cihhs-10361

37. Melo CMM. Divisão do trabalho e enfermagem. São Paulo: Cortez; 1986.

Recebido: 20 de dezembro de 2018 Aprovado: 4 de julho de 2019 Publicado: 4 de dezembro de 2019

A Revista Baiana de Enfermagem utiliza a Licença Creative Commons - Atribuição-NãoComercial 4.0 Internacional. https://creativecommons.org/licenses/by-nc/4.0/

Este artigo é de acesso aberto distribuído sob os termos da Licença Creative Commons (CC BY-NC). Esta licença permite que outros remixem, adaptem e criem a partir do seu trabalho para fins não comerciais. Embora os novos trabalhos tenham de lhe atribuir o devido crédito e não possam ser usados para fins comerciais, os usuários não têm de licenciar esses trabalhos derivados sob os mesmos termos. 